ISSN: $2594-4827$

\title{
CONTRIBUIÇÕES DA EDUCAÇÃO FÍSICA À FORMAÇÃO HUMANA INTEGRAL NO ENSINO MÉDIO INTEGRADO ${ }^{1}$
}

\author{
Eder Márcio Araujo Sobrinho \\ Rosa Oliveira Marins Azevedo ${ }^{3}$ \\ Vanderlei Antonio Stefanuto ${ }^{4}$
}

\section{RESUMO}

O presente artigo constitui-se de uma reflexão teórica sobre a Educação Física como componente curricular obrigatório no Ensino Médio Integrado. Partindo do desenvolvimento da disciplina no contexto escolar brasileiro, desde sua origem com cunho militarista e higienista, até a chegada do movimento renovador que trouxe novas concepções e correntes metodológicas com enfoque na cultura corporal, com ideais que se relacionam com a formação humana integral ou omnilateral. Nesse sentido, tivemos como objetivo identificar quais as contribuições da Educação Física enquanto componente curricular à Formação Humana Integral no Ensino Médio Integrado. Para tanto, baseamo-nos nos conceitos da abordagem critico-superadora da Educação Física. Essa abordagem busca a superação de um modelo tecnicista e mecanicista, focada na relevância social dos conteúdos propostos pela Educação Física no Ensino Médio, proporcionando ao aluno a capacidade de compreender e intervir de maneira eficaz na realidade social que vive. Nesse sentido a Educação Física, com base na cultura corporal, pode contribuir para a Formação Humana Integral, oferecendo uma oportunidade de articulação entre os saberes próprios do componente curricular com as questões ligadas ao mundo do trabalho e, consequentemente, contribuem para que os alunos possam agir com mais autonomia, tendo uma visão crítica sobre aspectos socioculturais os quais estão inseridos.

Palavras-chave: Educação Física; Formação Humana Integral; Ensino Médio Integrado.

\footnotetext{
${ }^{1}$ Uma versão preliminar desse texto foi apresentada no I Simpósio Amazônico em Educação Profissional e Tecnológica, promovido pelo ProfEPT/IFAM/CMC, realizado em Manaus, Amazonas, nos dias 28 e 29/11/2018.

2 Estudante do Mestrado em Educação Profissional e Tecnológica do Instituto Federal de Educação, Ciência e Tecnologia do Amazonas. E-mail: marcio.sobrinho@ifam.edu.br

${ }^{3}$ Doutora em Educação em Ciências e Matemática. Professora do Mestrado em Educação Profissional e Tecnológica do Instituto Federal de Educação, Ciência e Tecnologia do Amazonas. E-mail: marinsrosa@yahoo.com.br

${ }^{4}$ Doutor em Biologia na Agricultura e no Ambiente. Professor do Mestrado em Educação Profissional e Tecnológica do Instituto Federal de Educação, Ciência e Tecnologia do Amazonas. E-mail: vanderstefanuto13@gmail.com
} 


\title{
CONTRIBUTIONS OF PHYSICAL EDUCATION TO THE INTEGRAL HUMAN FORMATION IN HIGH SCHOOL
}

\begin{abstract}
This article is a theoretical reflection on Physical Education as a compulsory curricular component in Integrated High School. Starting from the development of the subject in the Brazilian school context since its origin in the militaristic and hygienist fields until the arrival of the renovating movement that brought new conceptions and methodological currents with focus on the body culture, with ideals that are related to the integral or omnilateral human formation. In this sense, we aimed to identify the contributions of Physical Education as curricular component to Integral Human Education in Integrated Secondary Education. Therefore, we are based on the concepts of the critical-overcoming approach of Physical Education. This approach seeks to overcome a technicist and mechanistic model, focused on the social relevance of the contents proposed by Physical Education in High School, giving the student the ability to understand and intervene effectively in the social reality that he lives. In this sense, Physical Education, based on body culture, can contribute to Integral Human Formation by offering an opportunity for articulation between the knowledge specific to the curricular component with issues related to the world of work and, consequently, contribute to enable students to act with more autonomy and have a critical view on sociocultural aspects in which they are inserted.
\end{abstract}

Keywords: Physical Education; Integral Human Formation; Integrated High School.

\section{INTRODUÇÃO}

A Educação Física Escolar no Brasil, ao longo das últimas décadas, vem passando por um processo de ressignificação de sua prática pedagógica. Se no início de sua inserção no universo escolar, por meio da LDB de 1971, a disciplina esteve pautada pela prevalência de conteúdos ligados estritamente às práticas corporais com caráter higienista e tecnicista, a partir dos anos de 1980, em meio ao processo de redemocratização, surge o que Soares et al. (2012), denominaram de Movimento Renovador da Educação Física.

Segundo Caparroz (1997), esse movimento ficou marcado por um conjunto de produções e debate com esforço de reordenação dos pressupostos orientadores da Educação Física, todas as discussões envolvendo a prática pedagógica dessa área resultaram no surgimento de diversas abordagens e concepções que culminaram na legitimação da Educação Física, não apenas como atividade, mas sim como componente curricular pela Lei de Diretrizes e Bases da Educação Nacional - LDB 9394/96 
(BRASIL, 1996), no sentido de superação de uma atividade escolar focada apenas nas práticas voltadas para a promoção de desenvolvimento físico e esportivo.

Segundo Boscatto (2017), a Educação Física a partir da nova LDB, obtém o caráter de um componente que integra o currículo da escola e, nesse caso, é responsável por um conjunto de conhecimentos oriundos da cultura corporal que devem contribuir com a formação cidadã dos sujeitos em uma sociedade democrática. Tais características presentes na proposta de renovação da Educação Física vão ao encontro dos ideais de formação humana integral ou omnilateral.

De acordo com Frigotto, Ciavatta e Ramos (2005), pensar uma educação integral é garantir ao adolescente, ao jovem e ao adulto trabalhador o direito a uma formação completa para a leitura do mundo e para a atuação como cidadão pertencente a um país, integrado dignamente à sua sociedade política.

Com base nessas considerações, objetivamos nesse estudo identificar quais as contribuições da Educação Física enquanto componente curricular à Formação Humana Integral no Ensino Médio Integrado. Para tanto, utilizaremos uma metodologia de cunho crítico-teórico, baseada em dados secundários, ou seja, fundamentada em material já publicado, em busca de uma visão holística sobre o fenômeno em foco (GIL, 2002, p.44-5). Primeiramente trataremos de questões ligadas a Omnilateralidade, sequencialmente focalizaremos a Educação Física, suas concepções e objetivos. Ao final da tessitura textual, abordaremos o Ensino Médio Integrado e suas possíveis contribuições da Educação Física para formação humana integral dos alunos dessa modalidade de ensino.

\section{FORMAÇÃO HUMANA INTEGRAL}

Tornar os estudantes o centro das finalidades do Ensino Médio e superar sua histórica vinculação com o mercado de trabalho, são fatores que, de acordo com Ramos (2007) fundamentam a construção de um projeto educacional, no contexto dessa etapa da educação básica, considerando o sentido da formação integral ou omnilateral.

Seguindo nessa concepção, Ciavatta (2005) propõem algumas reflexões sobre o tema: Qual o tipo de sociedade que buscamos construir quando educamos? Como os sistemas de ensino devem contribuir para formação de cidadão críticos e reflexivos, 
capazes de transformar a realidade social a qual estão inseridos? Para a autora é preciso tratar a educação como uma totalidade social, isto é, nas múltiplas mediações históricas que concretizam os processos educativos, ou seja, uma escola unitária.

Neste cenário, Ramos (2008) sugere uma concepção de escola unitária, que seja capaz de superar a dualidade educacional brasileira.

\begin{abstract}
A luta contra isso é uma luta contra hegemônica. É uma luta que não dá tréguas e que, portanto, só pode ser travada com muita força coletiva. A concepção da escola unitária expressa o princípio da educação como direito de todos. Uma educação de qualidade, uma educação que possibilite a apropriação dos conhecimentos construídos até então pela humanidade, o acesso a cultura, etc. Não uma educação só para o trabalho manual e para os segmentos menos favorecidos, ao lado de uma educação de qualidade e intelectual para o outro grupo. Uma educação unitária pressupõe que todos tenham acesso aos conhecimentos, à cultura e às mediações necessárias para trabalhar e para produzir a existência e a riqueza social (RAMOS, 2008, p.2).
\end{abstract}

Colaborando, Frigotto, Ciavatta e Ramos (2005) sugere que, pensar uma educação integral é garantir ao adolescente, ao jovem e ao adulto trabalhador o direito a uma formação completa para a leitura do mundo e para a atuação como cidadão pertencente a um país, integrado dignamente à sua sociedade política.

Nesse contexto, Ramos (2008) propõe compreender a Formação Humana Integral ou Omnilateral por meio das dimensões fundamentais da vida que estruturam a prática social: o trabalho, a ciência e a cultura.

O trabalho compreendido como realização humana inerente ao ser (sentido ontológico) e como prática econômica (sentido histórico associado ao respectivo modo de produção); a ciência compreendida como os conhecimentos produzidos pela humanidade que possibilita o contraditório avanço produtivo; e a cultura, que corresponde aos valores éticos e estéticos que orientam as normas de conduta de uma sociedade (RAMOS, 2008, p.4).

Em seu texto "Concepções do Ensino Médio Integrado", Ramos (2008) estabelece a relação indissociável entre trabalho, ciência e cultura, para a autora isso significa compreender o trabalho como princípio educativo, o que não se confunde com o "aprender fazendo", nem é sinônimo de formar para o exercício do trabalho. Considerar o trabalho como princípio educativo equivale dizer que o ser humano é produtor de sua realidade e, por isto, se apropria dela e pode transformá-la.

Desse modo, Ramos (2008) segue sua reflexão apresentando as possibilidades de 
construção de um projeto de ensino médio no sentido da formação humana integral, para ela, é preciso que superemos a dualidade entre formação específica e formação geral. Sobre a superação do tradicional dualismo educacional brasileiro, Frigotto, Ciavatta e Ramos (2005) trazem o enfoque ao primeiro projeto de LDB, após o processo de redemocratização do Brasil que, sob a liderança do Fórum Nacional em Defesa da Escola Pública, teve intensa participação da comunidade acadêmica e o apoio de parlamentares de vários partidos progressistas. Nele buscava-se assegurar uma formação básica que superasse a dualidade entre cultura geral e cultura técnica, assumindo o conceito de politecnia.

Para que isso aconteça, Ramos (2008) defende que é necessário garantir o direito de acesso aos conhecimentos socialmente construídos, tomados em sua historicidade, sobre uma base unitária que sintetize humanismo e tecnologia tendo o trabalho como princípio educativo.

Segundo Frigotto (1989), para que o trabalho se torne manifestação de vida e, portanto, educativo é preciso superar sua visão reducionista. Para o autor a consciência crítica é o primeiro elemento desse processo, possibilitando entender o trabalho em si, como meio pelo qual o homem transforma a natureza e se relaciona com os outros homens para produção de sua própria existência.

Ramos (2007) enfatiza que o homem produz conhecimentos que, sistematizados sob o crivo social e por um processo histórico, constitui a ciência. Uma formação integrada, portanto, deve possibilitar não apenas o acesso a conhecimentos científicos, mas também promover um modo de pensar crítico da sociedade.

Nesse sentido, a ideia de formação humana integral, coincide com a metodologia de ensino, específica da Educação Física, intitulada crítico-superadora.

A metodologia de ensino crítico-superadora expõe que o objeto de conhecimento da educação física é a categoria cultura corporal, que engloba as práticas corporais como: o jogo, a dança, o esporte, a luta, a brincadeira, entre outros. Defende-se que essa categoria deve ser compreendida como um conjunto de atividades que foram apropriadas e objetivadas pelos seres humanos com base em certa necessidade social. Promulga, também, que o ensino das atividades oriundas da cultura corporal deve ser transmitido pelo professor e assimilado pelo aluno tendo como principal balizada contribuir para a formação omnilateral do indivíduo e para a superação do modo de produção capitalista (BERNARDO SILVA; CAVAZOTTI, 2017, p. 2). 
Na perspectiva de uma Educação Física para além da mera prática de exercícios físicos ou da esportivização, discutiremos na próxima seção os caminhos percorridos por esse componente curricular no ensino médio e o processo de ressignificação que vem passando ao longo das últimas décadas.

\section{EDUCAÇÃO FÍSICA NO ENSINO MÉDIO: CONCEPÇÕES E OBJETIVOS}

Desde sua introdução nas instituições escolares brasileiras até o momento atual, a Educação Física passou por um processo de evolução e transformação. Foi implantada como componente curricular com o parecer de Rui Barbosa em 1882 e ao longo das décadas finais do século XIX e início do século XX, sofrendo forte influência militar. Nas escolas eram comuns aulas onde o professor exercia o papel de instrutor e o aluno de recruta.

Nesse período também, a Educação Física sofria forte influência médica, com princípios higienistas que pregavam hábitos saudáveis e higiênicos, tendo como perspectiva a formação de um homem esteticamente forte e biologicamente saudável. Essas abordagens foram muito significativas, principalmente no período da $1^{\circ}$ e da $2^{\circ}$ guerra mundial. Após as grandes guerras, no entanto, a Educação Física passa a assumir um caráter desportivo.

Nesse novo momento, o professor passa a assumir dentro da escola o papel de treinador, sendo o aluno encarado como atleta. É nesse período que podemos observar uma forte tendência a exclusão daqueles alunos que não conseguiam desenvolver as capacidades motoras específicas para se tornarem talentos esportivos.

O esporte passou a ocupar cada vez mais espaço nas aulas de Educação Física, enaltecendo as marcas de rendimentos, os recordes, a competitividade, o desempenho e os índices físicos. Embora, em todos esses momentos houvesse um caráter tecnicista, o auge dessa influência foi mais forte nos anos 70, onde se estreitam os vínculos entre esporte e nacionalismo (SANTOS, 2016, p. 2).

Passado esse período de forte esportivização, a partir dos anos 1980 a Educação Física Escolar passou a ter como enfoque principal, o desenvolvimento psicomotor do aluno, tirando da escola a papel de descobrir, aperfeiçoar e formar atletas de alto rendimento. 
De acordo com Hurtado (1983), é nesse momento que a Educação Física passou então a dedicar esforços no sentido de promover o desenvolvimento físico, social, emocional e mental dos estudantes por meio da atividade corporal. Com isso, tornou-se evidente que os professores deveriam preocupar-se com o desenvolvimento integral do aluno, como ser convivente e agente da sociedade, possuidor de vontade e limitações.

Assim, atualmente a Educação Física escolar no âmbito do Ensino Médio, é resultado das diversas influências e correntes metodológicas que surgiram a partir desse período. Segundo Zago e Galante (2010), as concepções Desenvolvimentista, Construtivista, Sistêmica e Crítico-Superadora da Educação Física, mesmo que, por vezes, apresentem divergências em relação à metodologia que deve ser adotada pelos sistemas de ensino, possui em comum um pensamento filosófico total de homem, ou seja, o indivíduo é visto como uma unidade, numa preocupação com o ser humano.

A Educação Física está inserida na grade curricular das escolas de ensino médio como uma disciplina que tem como princípio o aprimoramento da cultura corporal do movimento. Atualmente sua legitimidade no âmbito escolar está expressa através da Lei de Diretrizes e Bases da Educação Nacional - LDB n 9394/96 que no art. 26, §3 diz que "A educação física, integrada à proposta pedagógica da escola, é componente curricular obrigatório da Educação Básica, ajustando-se às faixas etárias e às condições da população escolar, sendo facultativa nos cursos noturnos” (BRASIL, 1996).

Os PCNs enfatizam ainda que, a Educação Física precisa buscar sua identidade como área de estudo fundamental para a compreensão e entendimento do ser humano, enquanto produtor de cultura. Nesse sentido, o que se deseja do aluno do Ensino Médio é uma ampla compreensão e atuação das manifestações da cultura corporal.

Projetos como a elaboração de jogos, resgate de brincadeiras populares, narração de fatos e elaboração de coreografias podem estar perfeitamente articulados com Português, História, Geografia, Sociologia etc. Esclarece-se que a via de integração não é única, e sim de duas mãos, o que significa que as demais áreas devem utilizar-se do movimento, buscando também integrar-se de forma eficiente com a Educação Física ( BRASIL, 1999, p.40)

Nessa perspectiva, de uma estruturação das aulas com base em abordagens pedagógicas focadas da cultura corporal do movimento, podemos destacar a corrente crítico-superadora, como aquela que apresenta uma maior relação entre sua proposta e os princípios presentes nos documentos norteadores. Segundo Darido (2003), essa 
abordagem busca a superação de um modelo tecnicista e mecanicista. Assim, a abordagem crítico-superadora busca a relevância social dos conteúdos propostos pela Educação Física no Ensino Médio, os alunos devem ainda estabelecer a relação entre o conhecimento científico e o senso comum ligado às práticas corporais.

Contribuindo, Santos e Zaffalon Junior (2007) afirmam que essa abordagem no Ensino Médio, proporciona ao aluno a capacidade de compreender e intervir de maneira eficaz na realidade social que vive.

A Educação Física nesta concepção é entendida como uma disciplina que trata do jogo, da ginástica, do esporte, da dança, da capoeira, e de outras temáticas como sendo um conhecimento da cultura corporal de movimento, e esta cultura corporal compreendida como o conjunto de atividades culturalmente produzidas pelo homem e historicamente situadas (SANTOS; ZAFFALON JUNIOR, 2007, p. 37).

No entanto, a Educação Física enfrenta no Ensino Médio algumas dificuldades relacionadas à organização curricular. Boscatto (2017) aponta que o contexto histórico da disciplina, sobretudo as questões ligadas ao fenômeno esportivo e as práticas corporais relacionadas à promoção de saúde são os principais discursos de legitimidade pedagógica e que permeiam os conteúdos de ensino.

Nesse contexto, Miranda, Lara e Rinaldi (2009) apontam que muitos professores têm dificuldade acerca do que ensinar na Educação Física escolar. Segundo os autores, as questões ligadas à saúde e também viés biológico, representam a base para o currículo, sinalizando claramente a necessidade de uma sistematização dos conhecimentos da Educação Física no Ensino Médio.

Colaborando, Boscatto (2017) salienta que é necessária uma organização curricular para a Educação Física. $\mathrm{O}$ autor acredita que, somente com essa estruturação, o componente curricular poderá contribuir com a melhoria do processo de ensinoaprendizagem, ampliando e diversificando os conteúdos de ensino e, também, oferecendo ao professor um suporte para a prática pedagógica cotidiana.

Ainda de acordo com Boscatto (2017), torna-se fundamental refletir sobre o papel atual da Educação Física no ensino médio, seu engajamento ao projeto pedagógico, atendendo aos preceitos legais vigentes, contribuindo para sua legitimidade como componente indispensável ao currículo escolar, que lida com um saber próprio, que assim como as demais disciplinas é indispensável para formação dos estudantes. 


\section{EDUCAÇÃO FÍSICA E O ENSINO MÉDIO INTEGRADO}

O Ensino Médio Integrado no Brasil instituiu-se em 2004, por meio do Decreto $\mathrm{n}^{\circ}$ 5.154/2004, visando à articulação entre o Ensino Médio e a Educação Profissional, numa perspectiva de integração entre os conhecimentos relacionados ao trabalho, à ciência, à tecnologia e à cultura.

A partir desse decreto, fica clara a possibilidade de superar a dualidade estrutural histórica no Ensino Médio brasileiro, como algo que transcenda uma formação profissional voltada meramente para suprir as necessidades do mercado de trabalho, e que se constitua a possibilidade de travessia para a formação humana integral, capaz de tornar os estudantes autônomos, críticos e reflexivos.

Segundo Boscatto (2017) nesse caso, o ensino de caráter propedêutico deve ser desenvolvido de forma articulada com a formação profissional.

Com isso, os saberes historicamente produzidos pelas ciências, pelas artes, pelas linguagens, pela filosofia, etc., devem ser sistematizados pelos diferentes componentes curriculares, de forma a atenderem às necessidades contemporâneas exigidas na formação para o exercício da cidadania e da atuação profissional (BOSCATTO, 2017, p. 3).

Nessa perspectiva, de acordo com as Diretrizes Curriculares Gerais da Educação Básica:

A identidade do Ensino Médio se define na superação do dualismo entre propedêutico e profissional. Importa que se configure um modelo que ganhe uma identidade unitária para esta etapa e que assuma formas diversas e contextualizadas da realidade brasileira (BRASIL, 2013, p.214).

Diante desse entendimento, Frigotto (2012) acrescenta que, a função social do Ensino Médio Integrado a Educação Profissional Tecnológica, baseia-se na construção de um projeto de desenvolvimento com justiça social. Para o autor é fundamental que o Ensino Médio nessa perspectiva promova a "[...] efetiva igualdade, e consequentemente uma democracia e cidadania substantivas, de forma que, ao mesmo tempo, responda aos imperativos das novas bases técnicas da produção, preparando para o trabalho complexo" (FRIGOTTO, 2012, p. 73).

Inserido nesse contexto, é imprescindível que a Educação Física busque o engajamento nesse projeto educacional, contribuindo para a formação humana integral. Isso sugere uma superação do modelo de aulas apoiadas em conteúdos tecnicistas, ou 
seja, além do esporte, a disciplina deve desenvolver conteúdos ligados ao mundo do trabalho, focando nos elementos provenientes da cultura corporal:

As práticas corporais relacionam-se estreitamente com o corpo humano. Existem aspectos biológicos (fisiológicos, anatômicos) e culturais (relações com o contexto social) que interferem e constituem o desenvolvimento corporal. É importante que os estudantes do ensino médio integrado problematizem e compreendam como se constitui e se desenvolve o corpo humano nos âmbitos do trabalho, das práticas corporais sistematizadas, da saúde, do lazer e dos demais contextos socioculturais (BOSCATTO, 2017, p. 115).

Os conhecimentos sobre o corpo e as práticas corporais, oferecem uma oportunidade de articulação entre os saberes próprios da Educação Física com as questões ligadas ao mundo do trabalho e, consequentemente, contribuem para que os alunos tenham uma visão crítica sobre aspectos citados por Boscatto (2017), como corpo e trabalho, saúde e qualidade de vida, violência/preconceitos/discriminação social, tecnologias de informação e cultura digital e nutrição.

Observamos então a preocupação em estabelecer um grau de relevância a Educação Física escolar, visto que historicamente o componente teve sua prática pedagógica muito questionada sobre sua importância dentro do contexto escolar. Nesse aspecto, Silva; Silva; Molina Neto (2016), afirmam que, é necessário aos professores de Educação Física um posicionamento claro sobre o conhecimento e a ação pedagógica da disciplina. Os autores alertam para necessidade de, cada vez mais, legitimar a Educação Física como componente curricular imprescindível para uma formação integrada.

Dentre as temáticas e conteúdos atribuídos a cultura corporal, Gariglio (2002) destaca que a vinculação feita entre saúde e trabalho no âmbito da Educação Física dá ao componente curricular argumentos imprescindíveis para o sua visibilidade e reconhecimento dentro das instituições de ensino.

Reforçando a importância do desenvolvimento desses conhecimentos e indo mais além, Palma (2001) atribui ao campo da Saúde Pública um pensamento além do biológico, pois, segundo o autor, os problemas de saúde existentes em todo mundo estão relacionados às desigualdades sociais e aos problemas fundamentais da distribuição da riqueza.

Seguindo nessa perspectiva Silva, Silva e Molina Neto (2016) apontam a necessidade da construção de uma base curricular para a Educação Física, pois, 
entendem que o viés biológico e instrumental aplicado atualmente, limita as possibilidades de uma formação cidadã e emancipada que o componente curricular pode possibilitar.

Recentemente, Boscatto (2017) assinala sobre a necessidade de que os estudantes do Ensino Médio Integrado tenham acesso a conhecimentos que ultrapassem o caráter funcional, restritos à prevenção de patologias, por meio de exercícios físicos e de práticas esportivas. Para o autor, é preciso:

[...] possibilitar práticas de ensino da EF em que os sujeitos tenham acesso a uma base de conhecimentos curriculares que lhes possibilite dominar diferentes áreas e habilidades, desenvolver técnicas, mas que também, os auxiliem a "ler a sociedade" e, com isso, o desenvolvimento da ciência e da tecnologia (BOSCATTO, 2017, p.65).

Seguindo os princípios norteadores para o Ensino Médio Integrado, a Educação Física contribui para que os estudantes tenham subsídios que os possibilitem agir com mais autonomia em seu cotidiano:

É importante que os estudantes vivenciem, pratiquem, discutam e, sobretudo, compreendam os aspectos socioculturais inerentes às práticas corporais. A tematização crítica dos elementos que compõem a cultura corporal pode fornecer aos estudantes mais condições de compreender como é organizado o fenômeno esportivo e as suas características, as concepções de corpo, saúde e estética que a mídia propaga as relações entre gênero e mercado de trabalho presentes no meio esportivo e na sociedade, entre outras (BOSCATTO, 2017, p. 5).

Corroborando com o tema, Tenório et al. (2012) apontaram em seu estudo, uma proposta curricular na direção crítico-emancipatória da Educação Física, tendo como meta, não apenas a ampliação da empregabilidade dos estudantes, mas também, contribuindo para a consolidação de uma formação humana para a sociabilidade, construindo um sentimento de pertencimento e ressignificação ao contexto sociocultural, o qual está inserido.

\section{CONSIDERAÇÕES FINAIS}

Esse estudo possibilitou compreender melhor a especificidade da Educação Física enquanto componente curricular do Ensino Médio Integrado a Educação Profissional e 
Tecnológica, apresentando aspectos ligados à prática pedagógica da disciplina e sua inserção no ambiente escolar.

Percebemos que, a Educação Física ao longo dos anos, passou por diversas fases e correntes pedagógicas. Inicialmente apoiando-se em instituições como a militar, a médica e a esportiva ligada ao contexto tecnicista e viés biológico, centrava-se no desenvolvimento da aptidão física, na promoção da saúde e na descoberta de talentos esportivos no contexto escolar. No entanto, com o desenvolvimento acadêmico e científico da área, esse componente curricular, passou por um processo de superação, de uma prática voltada apenas ao desenvolvimento físico e esportivo dos estudantes, passando então a desenvolver um conjunto de conhecimentos da Cultura Corporal, objetivando contribuir com a formação cidadã dos alunos em uma sociedade democrática.

Nesses termos, a Educação Física, com base na Cultura Corporal se aproxima do conceito de Formação Humana Integral, visando à superação do dualismo educacional brasileiro entre a formação propedêutica e a formação profissional, tendo como perspectiva a integração entre os conhecimentos relacionados ao trabalho, à ciência, à tecnologia e à cultura.

Nessa perspectiva, a Educação Física tendo como base a metodologia críticoemancipatória, contribui juntamente com as demais unidades curriculares do Ensino Médio Integrado a Educação Profissional e Tecnológica, para a criação de mecanismos que possibilitem aos alunos o seu pleno desenvolvimento, tornando-os capazes de tomar decisões, assumindo responsabilidades com os princípios e valores éticos, de justiça, de solidariedade e respeito mútuo.

Portanto, a Educação Física no Ensino Médio Integrado, deve embasar-se em práticas pedagógicas que colabore para o desenvolvimento do conhecimento científico, histórico e sistêmico da cultura corporal, instrumentalizando e contribuindo para a efetivação da formação humana integral, por meio da socialização do conhecimento para a classe trabalhadora e, com isso, os conteúdos provenientes da organização desse componente curricular, levando à transformação social.

Evidenciamos também que, mesmo com a superação dos modelos tecnicistas e esportivistas da Educação Física, existe a necessidade de uma reorganização no planejamento de ensino e construção de uma base curricular para a Educação Física, no 
sentido de contribuir de forma eficaz, na articulação dos saberes próprios da cultura corporal com as demandas contemporâneas para a atuação profissional. Destacamos, a necessidade de aprofundamento no campo de estudos relacionados ao currículo da Educação Física no Ensino Médio Integrado.

Compreendemos que, na atualidade, a Educação Física enquanto componente curricular no Ensino Médio Integrado, exerce um papel que vai muito além da mera prática sistemática de exercícios físicos ou prática de modalidades esportivas. Hoje, a disciplina oferece uma gama de possibilidades e conteúdos da cultura corporal capazes de contribuir para articulação desses com as questões ligadas a formação humana integral, formando cada vez mais cidadãos autônomos e prontos para intervir de maneira crítica no meio sociocultural o qual estão inseridos.

\section{REFERÊNCIAS}

BRASIL. Decreto no 69.450, de 1 de novembro de 1971. Regulamenta o artigo 22 da Lei número 4.024, de 20 de dezembro de 1961, e alínea c do artigo 40 da Lei 5.540, de 28 de novembro de 1968 e dá outras providências. Diário Oficial da União, Brasília (1971 nov. 3); Sec. 1:8826.

BRASIL. Lei de Diretrizes e Bases da Educação Nacional. Lei nº 9394, de 20 de dezembro de 1996. Brasília, 1996.

BRASIL. Ministério da Educação, Secretaria da Educação Média e Tecnológica. Parâmetros Curriculares Nacionais: Ensino Médio / Ministério da Educação. Secretaria de Educação Média e Tecnológica / Brasília: Ministério da Educação, 1999.

BRASIL. Diretrizes Curriculares Gerais Nacionais para a Educação Básica. Ministério da Educação. Secretaria de Educação Básica. Diretoria de Currículos e Educação Integral. Brasília: MEC, SEB, DICEI, 2013.

BOSCATTO, J. D. Proposta curricular para a educação física no Instituto Federal de Santa Catarina: uma construção colaborativa virtual. 2017. Tese (Doutorado) Instituto de Biociências. Programa de Pós-Graduação em Desenvolvimento Humano e Tecnologias - Universidade Estadual Paulista. Rio Claro, 2017.

BERNARDO SILVA, M.; CAVAZOTTI, M. A. Contribuições da educação física escolar para o desenvolvimento psíquico do ser humano: primeiros apontamentos. Revista Ibero-Americana de Estudos em Educação, v. 12, p. 689-709, 2017. 
CIAVATTA, Maria. A escola e o trabalho como lugares de memória e de identidade. In: FRIGOTTO, Gaudêncio, CIAVATTA, Maria e RAMOS, Marise (orgs.). Ensino médio integrado: concepção e contradições. São Paulo: Cortez, 2005.

CAPARROZ, Francisco Eduardo. Entre a Educação Física na escola e a Educação Física da escola. Vitória: CEFD/UFES, 1997.

DARIDO, S. C. Educação Física na Escola: questões e reflexões. Guanabara, Rio de Janeiro: 2003.

FRIGOTTO, G. A produtividade da escola improdutiva. São Paulo: Cortez/Autores Associados, 1989.

FRIGOTTO, G.; CIAVATA, Maria; RAMOS, Marise (Orgs.). Ensino médio integrado: concepções e contradições. São Paulo: Cortez, 2005.

FRIGOTTO, G. Concepções e mudanças no mundo do trabalho e o ensino médio. In: FRIGOTTO, Gaudêncio; CIAVATA, Maria; RAMOS, Marise (Orgs.). Ensino médio integrado: concepções e contradições. 3. ed. São Paulo: Cortez, 2012.

GARIGLIO, J. Â. Educação Física no currículo de uma escola profissionalizante: um caso sui generis. Revista Brasileira de Ciências do Esporte, Campinas, v. 23. n. 2. p. 69-88, 2002.

GIL, A. C. Como elaborar Projeto de Pesquisa. 4. ed. São Paulo: Atlas, 2002.

HURTADO, J. G. G. M. O ensino da Educação Física: uma abordagem didática. 2.ed. Curitiba: Educa/Editer, 1983.

MIRANDA, A. C. M; LARA, L. M; RINALDI, I. P. B. A Educação Física no ensino médio: saberes necessários sob a ótica docente. Motriz, Rio Claro, v. 15, n. 3, p.621630, 2009.

PALMA, A. Educação Física, corpo e saúde: uma reflexão sobre outros "modos de olhar". Revista Brasileira de Ciências do Esporte, Campinas, v. 22, n. 2, p. 23- 39, 2001.

RAMOS, M. Concepção do ensino médio integrado à educação profissional. Natal: Secretaria de Educação do Estado do Rio Grande do Norte, 2007.

RAMOS, M. Concepção de ensino médio integrado. [S.1.: s.n.], 2008, p. 1-30. Disponível em: http://www. iiep.org.br/curriculo_integrado.pdf. Acesso em: 02 out. 2018.

SOARES, C. L., et al. Metodologia do Ensino de Educação Física. São Paulo: Cortez, 1992. 
SANTOS, M. H. T.; ZAFFALON JÚNIOR, J. R. As perspectivas da educação física no ensino médio. 2007. 45f. Trabalho de Conclusão de Curso (Graduação em Licenciatura Plena em Educação Física) - Universidade do Estado do Pará, Altamira, 2007.

SANTOS, E. M.; BARBOSA, E. S.; ALMEIRA. E.; MARINHO, E. F. A Educação Física no Ensino Médio: Conceitos e expectativas. Revista Gestão Universitária, 2016.

SILVA, M. A; SILVA, L. O; MOLINA NETO, V. Possibilidades da Educação Física no Ensino Médio Técnico. Movimento, Porto Alegre, v. 22, n. 1, 2016.

TENÓRIO, K. M. R; BEZERRA, B. B; SOUZA JÚNIOR, M; SILVA, P. N.G. MELO, M. S.T. Propostas curriculares Estaduais para Educação Física: uma análise do binômio intencionalidade-avaliação. Motriz, Rio Claro, v.18, n.3, 2012.

ZAGO, N.; GALANTE, R. C. Educação física no ensino médio: concepções e reflexões. Especialização em Educação Física Escolar do Departamento da Educação Física e motricidade humana, UFSCar, 2010. 